\title{
Spectral Sensitivity of the Extension Growth of Tulips Grown with Night Lighting under a Natural Photoperiod
}

\author{
Katsuhiko SUMITOMO ${ }^{1}$, Toshiaki TSUJI ${ }^{2}$, Atsuko YAMAGATA ${ }^{1,5}$, \\ Masaki ISHIWATA ${ }^{3}$, Makoto YAMADA ${ }^{3}$, Koji SHIMA ${ }^{4}$ and \\ Tamotsu HISAMATSU ${ }^{*}$
}

\footnotetext{
${ }^{1}$ National Institute of Floricultural Science, National Agriculture and Food Research Organization (Tsukuba, Ibaraki 305-8519, Japan)

${ }^{2}$ Horticultural Research Laboratory, Toyama Prefectural Agricultural, Forestry \& Fisheries Research Center (Tonami, Toyama 939-1327, Japan)

${ }^{3}$ Panasonic Electric Works Co., Ltd. (Kadoma, Osaka 571-8686, Japan)

${ }^{4}$ Horticultural Experiment Center, Wakayama Research Center of Agriculture, Forestry and Fisheries (Gobo, Wakayama 644-0024, Japan)
}

\begin{abstract}
The effect of light quality on the extension growth of tulips was investigated for 4 tulip (Tulipa gesneriana) cultivars "Leen van der mark," "Murasaki suisho," "Come back," and "Kikomachi." The exposure of tulips to ultraviolet-A (UV-A), blue (B), red (R) or far-red (FR) fluorescent tubes throughout the entire night (a process called "night lighting") was found to promote lengthening of the stem and first internode of plants grown under natural photoperiod conditions in a greenhouse. The effectiveness of FR night lighting was consistently observed across 4 cultivars, although the effectiveness of illumination within the UV-A, B and $\mathrm{R}$ wavelength ranges was found to vary with respect to stem length, the first internode and among different cultivars. Elevated photon flux densities of FR light were found to quantitatively increase the extension growth of "Leen van der mark," but the effect of FR night lighting reached saturation point at $0.59 \mu \mathrm{mol} \mathrm{m}^{-2} \mathrm{~s}^{-1}$. A 4-h end-of-day lighting period and night-break FR lighting period were also found to promote extension growth, but these effects were less pronounced than that induced by FR night lighting. A 4-h end-of-night FR lighting period had no effect on extension growth. Apart from these findings, the effects of the light quality on extension growth are discussed.
\end{abstract}

Discipline: Horticulture

Additional key words: elongation, end-of-day lighting, far-red light, night-break lighting

\section{Introduction}

The tulip (Tulipa gesneriana) is a perennial, bulbous plant. Control of stem elongation is important during growth because cut tulip flowers with long stems are in great demand. Significant research has been conducted with the aim of regulating the process of stem elongation of tulips as cut flowers. Prior to planting, tulip bulbs are stored at low temperature $\left(5-10^{\circ} \mathrm{C}\right)$, in order to induce early forcing tulip production, because they require cold temperatures for rapid extension growth of their stems. The extension growth of the stem depends upon the length of the cold storage period of the bulbs ${ }^{24}$. Various combinations with other treatments have been investigated in addition to cold storage to obtain further extension growth of the stem. Low growth temperatures produce longer cut flowers but markedly delay the time required

This paper reports the results obtained in the joint project on "Elucidation of biological mechanisms of photoresponse and development of advanced technologies utilizing light" sponsored by Ministry of Agriculture, Forestry and Fisheries.

Present address:

${ }^{5}$ Agricultural Experiment Station, Akita Prefectural Agriculture, Forestry and Fisheries Research Center (Yuwa, Akita 010-1231, Japan)

*Corresponding author: e-mail tamotsu@affrc.go.jp

Received 17 March 2011; accepted 18 May 2011. 
for flowering ${ }^{11}$, hence the extended greenhouse period was disadvantageous to production efficiency. Auxin and gibberellins (GA) are plant hormones that play key roles in tulip extension growth. As endogenous GA levels increase ${ }^{22}$, endogenous auxin levels have been found to increase in bioassays ${ }^{20}$, and auxin responsiveness is enhanced ${ }^{25}$ when plants undergo rapid elongation. Moreover, exogenous GAs and auxins stimulate extension growth in tulips ${ }^{28}$. However, GA-treated tulip plants were found to flower earlier than untreated plants, with no appreciable extension growth in the upper internodes, meaning the length of the cut flowers remained shorter ${ }^{12}$.

Light conditions regulate many aspects of plant growth and development, including stem extension and flowering. Light quality (spectrum or wavelength) is also important for the light response in plants. Recent developments in molecular genetic studies on the photoperiodic response in herbaceous species such as Arabidopsis and rice have revealed that photoreceptors are quite important for their light responses. Light signals are detected through plant photoreceptors, each of which has a specific sensitivity to a particular spectrum. Of the various photoreceptors, a family known as the phytochromes absorb a spectrum of light ranging from red (R) to far-red (FR) light, and 2 families of photoreceptors known as cryptochromes and phototropins absorb a spectrum from near-ultraviolet to blue (B) light. Light signaling through cryptochromes and phytochromes suppresses the extension growth of hypocotyls, epicotyls and stems in darkgrown plants ${ }^{1,6,4,15,16,18,31}$. Tulip plants grown under natural light, including B and R light, also undergo less stem extension than dark-grown plants ${ }^{19}$. Thus, the signals of $\mathrm{B}$ and R light (through cryptochromes and phytochromes) regulate extension inhibition relative to dark-grown plants in many cases.

Photoperiods affect extension growth in some species, and long day (LD) treatment promotes extension growth in a number of plants $3,7,10,13,32,34$. A 16-h LD treatment with warm white tubular fluorescent lamps was found to promote the extension growth of stems and produced longer cut flowers than 8 -h short-day conditions under low growing temperature $\left(9^{\circ} \mathrm{C}\right)^{11}$. Considering that photoreceptors should be involved in light perception in these LD responses, the LD signals from photoreceptors must promote extension growth. This claim is indeed inconsistent with the above descriptions that the signals from photoreceptors regulate extension inhibition in dark-grown plants, but the signals from photoreceptors must either have different effects or be regulated by different signaling pathways in light- and dark-grown plants.

The object of this research was to study the effect of light quality and promote stem extension by light treat- ment under greenhouse conditions in order to achieve longer cut tulip flowers. We did not attempt to demonstrate the effect of light quality relative to dark-grown plants as demonstrated by Okubo and Uemoto ${ }^{19}$. Instead, we attempted to show the effects of light quality for night lighting or LD treatments relative to the natural photoperiod (light-grown plants under the natural photoperiod of sunshine served as controls, and light treatments were conducted throughout the night in our experiments). First, we determined the spectral sensitivity of the extension growth of tulips grown with night lighting in order to determine the most effective spectrum to promote extension growth and demonstrated that it was FR light. Subsequently, two further experiments for testing the quantity and timing of exposure to FR light were conducted to collect data for the development of an appropriate lighting technique.

\section{Materials and methods}

\section{Experiment 1. Effect of light quality for night lighting}

All experiments were conducted at the National Institute of Floricultural Science (Tsukuba, Ibaraki, Japan, $36^{\circ} 2^{\prime} 46^{\prime \prime} \mathrm{N}$; $140^{\circ} 5^{\prime} 55^{\prime \prime} \mathrm{E}$ ). Tulip bulbs of "Leen van der mark," "Murasaki suisho," "Come back," and "Kikomachi" with circumferences of 11-12 cm were obtained from a commercial propagator and maintained at $20^{\circ} \mathrm{C}$ until the initiation of the cold treatment. Bulbs of the "Come back" cultivar were exposed to $15^{\circ} \mathrm{C}$ treatment from September 9 to 24, 2009 followed by $5^{\circ} \mathrm{C}$ treatment from September 24 to November 19, 2009. Bulbs of the "Leen van der mark," "Murasaki suisho" and "Kikomachi" cultivars were exposed to $15^{\circ} \mathrm{C}$ treatment from September 23 to October 6,2009 , followed by $5^{\circ} \mathrm{C}$ treatment from October 6 to December 14, 2009. Bulbs were planted ( 1 per pot) in $10.5-\mathrm{cm}$ i.d. plastic pots containing a commercial horticultural soil (Kureha-Engei-Baido; Kureha Chemical Co. Ltd, Tochigi, Japan) immediately after the $5^{\circ} \mathrm{C}$ treatment, and the plants were grown in a glasshouse maintained at an air temperature exceeding $13^{\circ} \mathrm{C}$. The greenhouse was ventilated when the air temperature exceeded $22^{\circ} \mathrm{C}$ under a natural photoperiod. The length of the natural photoperiod from sunrise to sundown was within the range 09.41-10.24 h during the light treatments. Liquid fertilizer consisting of $100 \mathrm{mg}$ $\mathrm{L}^{-1}$ nitrogen was administered as required.

The natural photoperiod was extended by illumination throughout the night (night lighting) from 6 different colored fluorescent tubes (Fig. 1; Panasonic Electric Works Co., Ltd., Osaka, Japan), which were used to illuminate in the 300-405 $\mathrm{nm}$ (ultra-violet-A; UV-A), 385545 nm (blue; B), 485-595 nm (green; G), 475-735 nm 


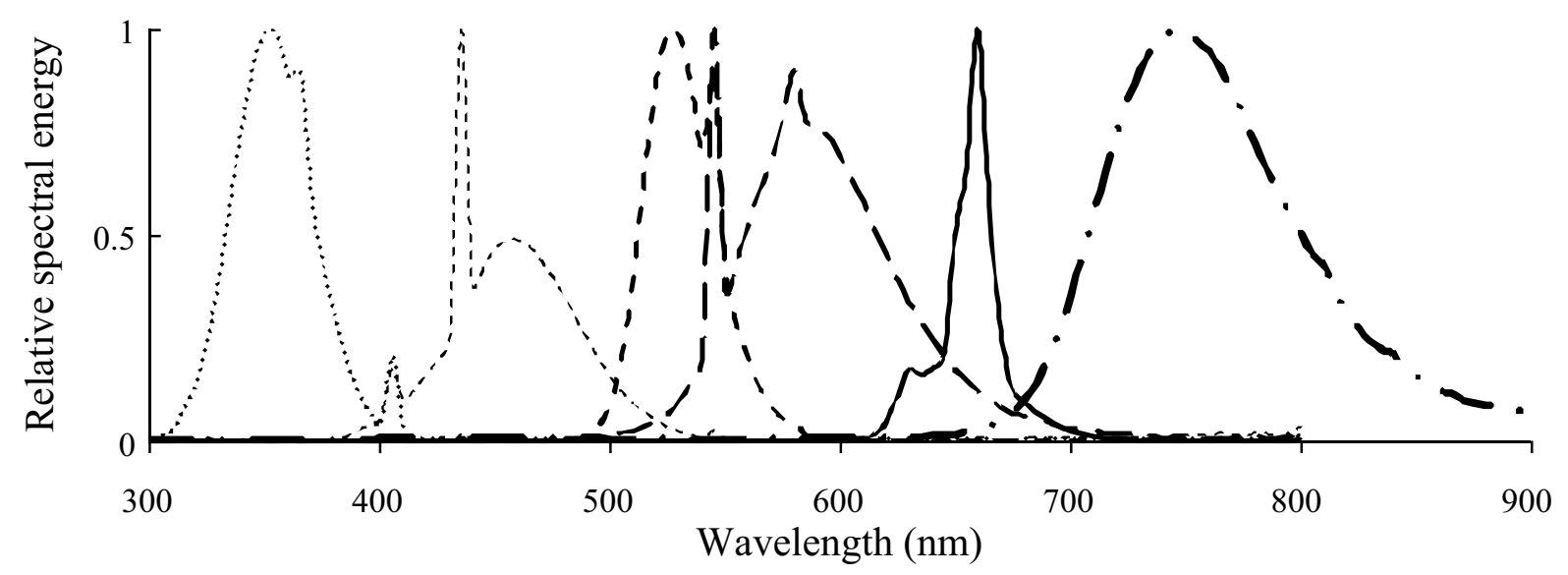

Fig. I. Relative spectral energy distribution of colored fluorescent tubes measured using a MCPD-3000 spectrometer scanning from 300 to $900 \mathrm{~nm}$

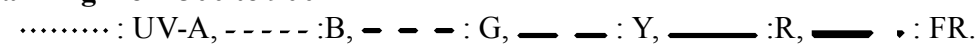

(yellow; Y), 595 - $730 \mathrm{~nm}$ (red; R), and 655-900 nm (farred; FR) regions. The photon flux densities (PFD) at the surface of the pot soil were $1.0 \mu \mathrm{mol} \mathrm{m} \mathrm{m}^{-2} \mathrm{~s}^{-1}$. The spectral distributions and PFDs of these fluorescent tubes were determined with a multichannel UV-visible spectrometer (MCPD-3000; Otsuka Electronics Co., Ltd., Tokyo, Japan). Each experimental unit was separated with curtains of white and silver polyethylene to prevent potential contamination with other light sources when the fluorescent tubes were turned on. Each treatment group included 14 plants.

The flowering date, the length of the first internode (measured from the stem bottom to the first leaf) and the stem length (measured from the stem bottom to the base of the petals) were recorded when the anther opened.

\section{Experiment 2. Effect of the PFD level of FR light}

Experiments were conducted in 2009-2010 and 2010-2011. Tulip bulbs of "Leen van der mark," 11-12 cm in circumference, were obtained and stored as described in Exp. 1. Bulbs were exposed to $15^{\circ} \mathrm{C}$ treatment from September 23 to October 6,2009 , followed by $5^{\circ} \mathrm{C}$ treatment from October 6 to December 14,2009 , or $15^{\circ} \mathrm{C}$ treatment from September 27 to October 9, 2010, followed by $5^{\circ} \mathrm{C}$ treatment from October 9 to December 7 , 2010.

A night lighting treatment using FR fluorescent tubes was applied at $0,0.7,2.2,5.8$, or $11.6 \mu \mathrm{mol} \mathrm{m}^{-2} \mathrm{~s}^{-1}$ at the surface of the pot soil in the experiment conducted in 2009-2010 and at $0,0.09,0.16,0.29,0.59$, or $0.78 \mu \mathrm{mol}$ $\mathrm{m}^{-2} \mathrm{~s}^{-1}$ in that conducted in 2010-2011. The PFD of the FR light was determined with a spectroradiometer (MS-
720; EKO Instruments Co., Ltd., Tokyo, Japan). Each experimental unit was separated to prevent possible contamination with other light as described above. In each of the treatment groups, 17 and 15 plants were used in the experiments conducted in 2009-2010 and 2010-2011, respectively. Growth measurements were conducted as described above.

\section{Experiment 3. Effect of timing of exposure of FR light}

Tulip bulbs of the "Leen van der mark" cultivar were obtained, stored, exposed to cold treatment, and grown as described in the 2010-2011 experiment in Exp. 2. The natural photoperiod was extended by including the exposure of light from an FR fluorescent tube throughout the night (night lighting, NL), a 4-h end-of-day period (EOD; from dusk), a night-break period (NB; 2200 to 0200 hours) or an end-of-night period (EON; from $4 \mathrm{~h}$ before dawn). The PFD of the FR light, determined with a MS720 spectroradiometer, was $0.59 \mu \mathrm{mol} \mathrm{m} \mathrm{m}^{-2} \mathrm{~s}^{-1}$ at the surface of the pot soil. Each experimental unit was separated to prevent possible contamination with other light as described in Exp. 1. Fifteen plants were used in each treatment group. Growth measurements were conducted as described in Exp. 1.

\section{Results}

\section{Experiment 1. Effect of light quality}

The number of days required for flowering from planting was essentially the same for all light treatments and for each cultivar (Fig. 2). Exposure of the tulips to the colored fluorescent tubes had no effect on flowering. 

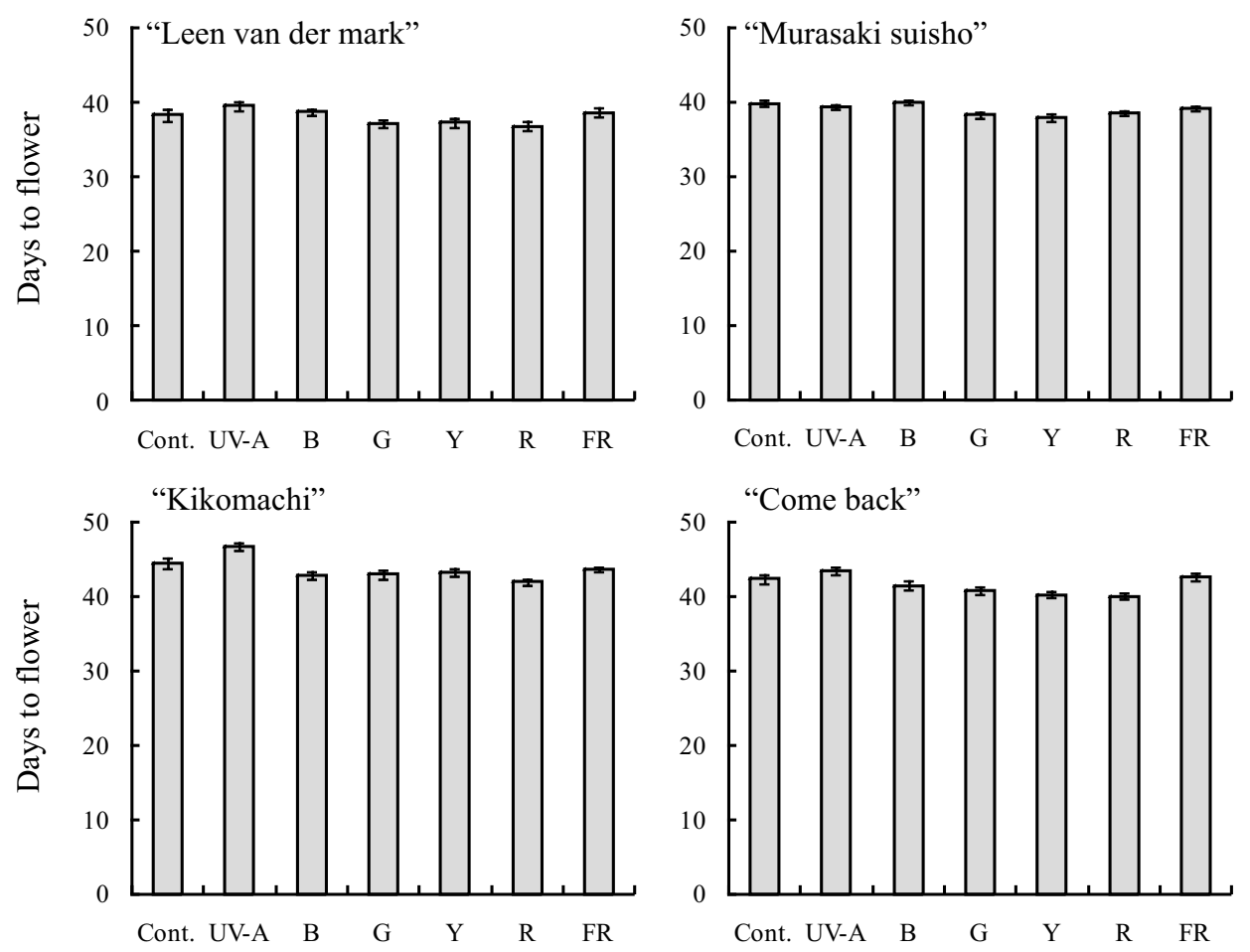

Colored fluorescent tubes

Fig. 2. Effect of exposure of the colored fluorescent tubes on the number of days required for flowering after planting of the tulip cultivars "Leen van der mark," "Murasaki suisho," "Kikomachi," and "Come back"

Exposures were applied throughout the night. The PFD at the surface of the pot soil was $1.0 \mu \mathrm{mol} \mathrm{m}^{-2} \mathrm{~s}^{-1}$. All values are mean \pm SE $(n=14)$.
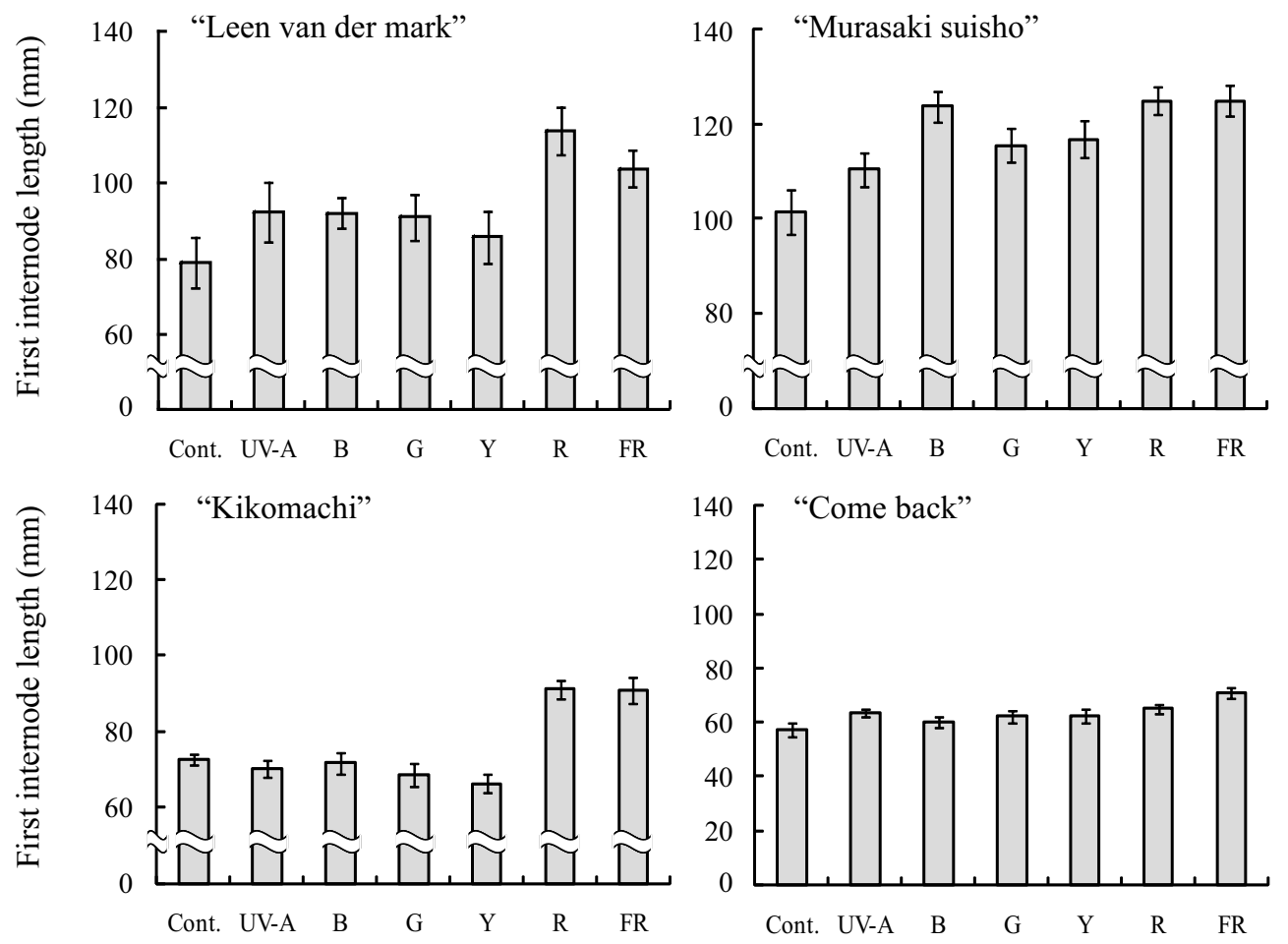

Fig. 3. Effect of exposure of the tulips to light from the colored fluorescent tubes on the first internode length in the tulip cultivars "Leen van der mark," "Murasaki suisho," "Kikomachi," and "Come back."

The conditions were the same as described for Fig. 2. 
In addition, exposure of the tulips to the colored fluorescent tubes did not impair extension growth. The effect was observed to vary between the stem and first internode and among the different cultivars. Exposure to the $\mathrm{R}$ and FR fluorescent tubes was found to markedly promote extension growth of the first internode, but exposure to the other fluorescent tubes had little effect on the extension growth of the "Leen var der mark" and the "Kikomachi" cultivars (Fig. 3). For the "Murasaki suisho" cultivar, each exposure treatment promoted extension growth of the first internode. In particular, longer first internode lengths were observed in plants exposed to the B, R, and FR fluorescent tubes. For the "Come back" cultivar, the first internode of the plants exposed to the FR fluorescent tube was the longest among all plants exposed to different light treatments. Other light treatments were found to slightly promote the extension growth of the first internode in the "Come back" cultivar.

The stem extension showed 2 different patterns of exposure responses to the colored fluorescent tubes among the different cultivars. In "Leen van der mark,"
"Kikomachi," and "Come back," exposures to R and FR light were most effective in promoting stem extension and produced equivalent effects (Fig. 4). The effects of UV-A and B light followed those of $\mathrm{R}$ and FR light, and there was no difference between the effect of UV-A and $\mathrm{B}$ in promoting stem extension. $\mathrm{G}$ and $\mathrm{Y}$ light also promoted stem extension, but their effects were less pronounced than those of other light treatments. In the case of "Murasaki suisho," B light was the most effective of all light treatments in promoting stem extension. This effect was followed, in order of effectiveness, by G, Y, R, and FR light. UV-A light showed little effect in promoting stem extension in this cultivar. Although the effect of spectrum on extension growth varied among the cultivars and between the stem and first internode, the effective spectra with respect to the promotion of extension growth indicated increased growths for the R/FR and UV-A/blue spectral ranges in general terms, while the effectiveness of FR light remained consistent across the 4 cultivars used in this experiment, meaning additional experiments were conducted to investigate the effect of quantity and timing of the exposure to FR light.
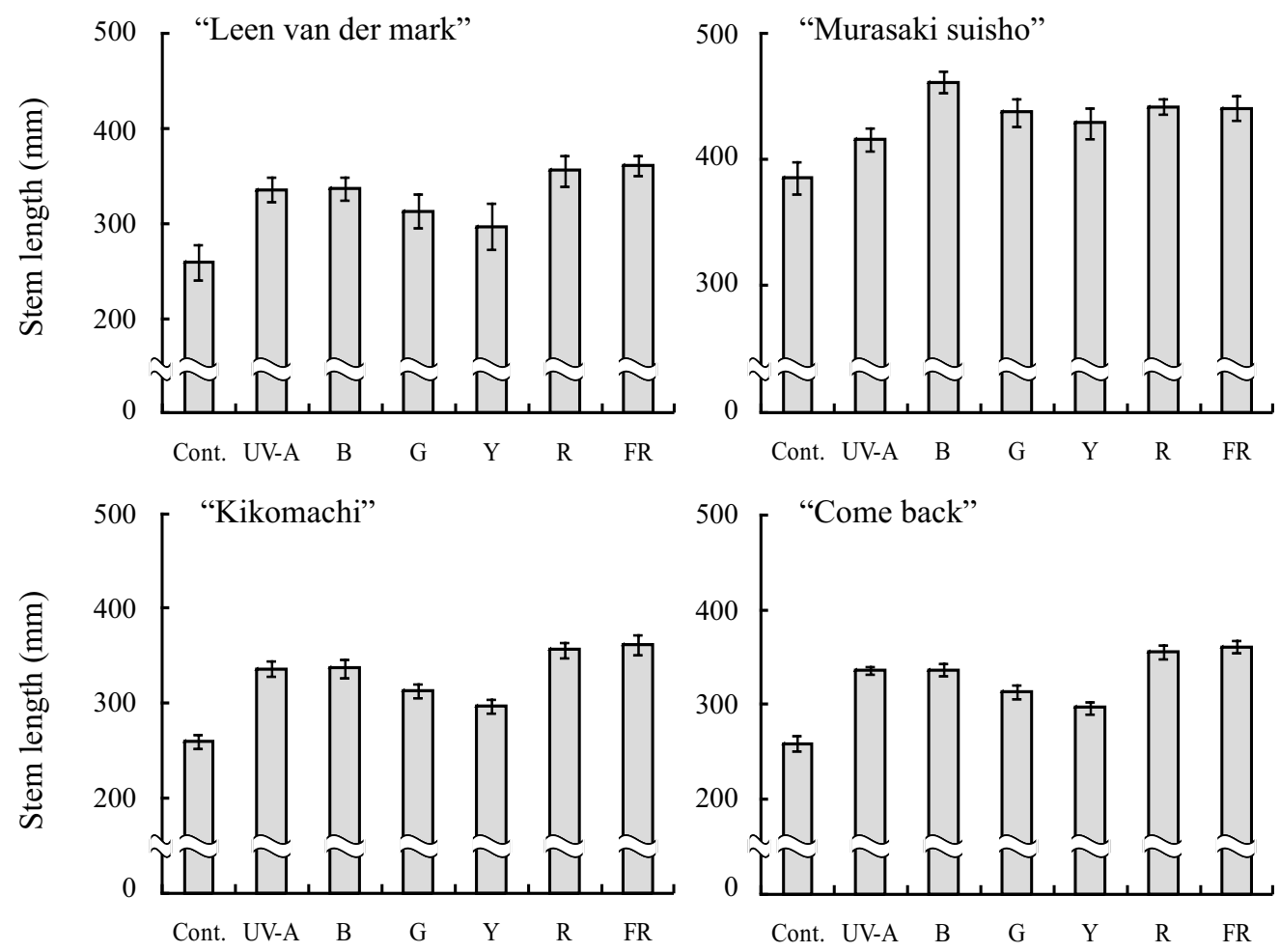

Colored fluorescent tubes

Fig. 4. Effect of exposure of the tulips to light from the colored fluorescent tubes on stem length in the tulip cultivars "Leen van der mark," "Murasaki suisho," "Ki komachi," and "Come back"

The conditions were the same as described for Fig. 2. 


\section{Experiment 2. Effect of the PFD level of FR light}

Plants treated with all the different light treatments reached the flowering stage after about 6.0 and 6.5 weeks respectively in the experiments conducted in 2009-2010 and 2010-2011, and on approximately the same date (data not shown). Extension growth of the stem and the first internode was found to increase by $43-54 \%$ and $25-35 \%$, respectively, with treatment of continuous FR night lighting. However, the effects with respect to promotion of extension growth remained essentially the same with elevated PFD levels of FR light ranging from 0.7 to 11.6 $\mu \mathrm{mol} \mathrm{m} \mathrm{m}^{-2} \mathrm{~s}^{-1}$ in the experiment conducted in 2009-2010 (data not shown). Night lighting of FR light at PFD levels exceeding $0.7 \mu \mathrm{mol} \mathrm{m} \mathrm{m}^{-2} \mathrm{~s}^{-1}$ was sufficient to promote extension growth. Therefore, we investigated the effect of exposure at lower levels of PFD in the experiment conducted in 2010-2011. The results showed that FR light quantitatively promoted extension growth. The length of the stem and the first internode rose as the PFD level of the FR light was increased to $0.59 \mu \mathrm{mol} \mathrm{m}{ }^{-2} \mathrm{~s}^{-1}$, but the effects in promoting extension growth were essentially identical between 0.59 and $0.78 \mu \mathrm{mol} \mathrm{m}^{-2} \mathrm{~s}^{-1}$ (Fig. 5). The effect of FR night lighting was saturated above $0.59 \mu \mathrm{mol}$ $\mathrm{m}^{-2} \mathrm{~s}^{-1}$.

\section{Experiment 3. Effect of timing of FR exposure}

Plants subjected to all the different treatments reached the flowering stage after about 6.5 weeks and on approximately the same date (data not shown). The results indicate that the effect of FR light on extension growth varies according to the timing of exposure. NL with FR light produced the greatest length of the stem and first internode (Fig. 6). EOD and NB FR lighting for 4-h was found to promote extension growth relative to the control. These effects involving the promotion of extension growth were almost the same, but were not as pronounced as observed with NL. Plants treated with EON FR lighting for 4-h had lengths of stem and the first internode almost equivalent to the control. Similar results have been observed for the chrysanthemum ${ }^{29}$.

\section{Discussion}

The light quality, quantity, timing, duration and direction of exposure must be considered when using light exposures for growth and flowering control. Our data include effective spectra with respect to promotion of the extension growth of tulips by night lighting and comparisons with plants grown under a natural photoperiod. The spectral ranges of UV-A, B, R and FR can promote extension growth. Although the effectiveness of UV-A, B, and $\mathrm{R}$ night lighting was found to vary among different cultivars, with respect to the stem and first internode, the FR night light was found to be the most consistent and effective light exposure feature for promoting these growth parameters of the 4 cultivars investigated in this study. Thus, we conclude that under the natural photoperiod, FR exposure consistently promotes extension growth. Two experiments were conducted to investigate the effect of quantity and timing of FR exposure. The promotion of extension growth by FR exposure was found to correlate with the PFD of the exposure, and this effect became sat-
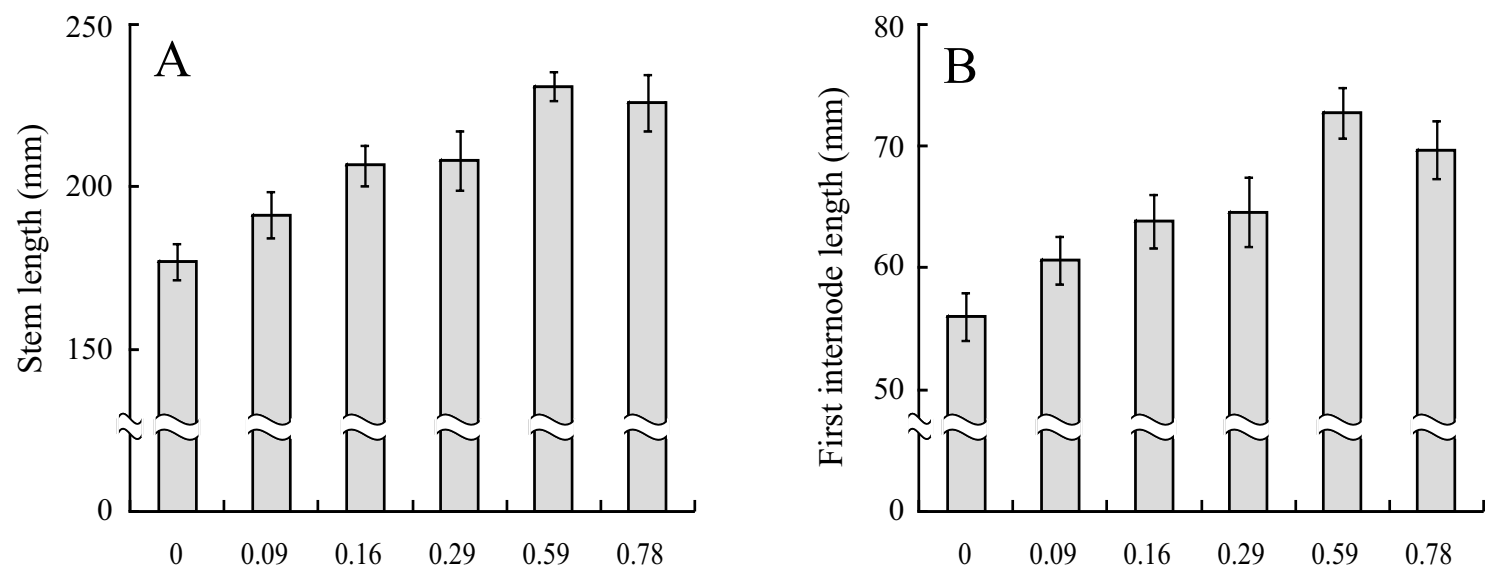

PFD level of FR light $\left(\mu \mathrm{mol} \mathrm{m}^{-2} \mathrm{~s}^{-1}\right)$

Fig. 5. Effect of the PFD level of exposure of the tulips to the light from the FR fluorescent tubes on the stem length and the first internode in the tulip cultivar "Leen van der mark"

Exposures were applied throughout the night. All values are mean $\pm \mathrm{SE}(\mathrm{n}=15)$. 

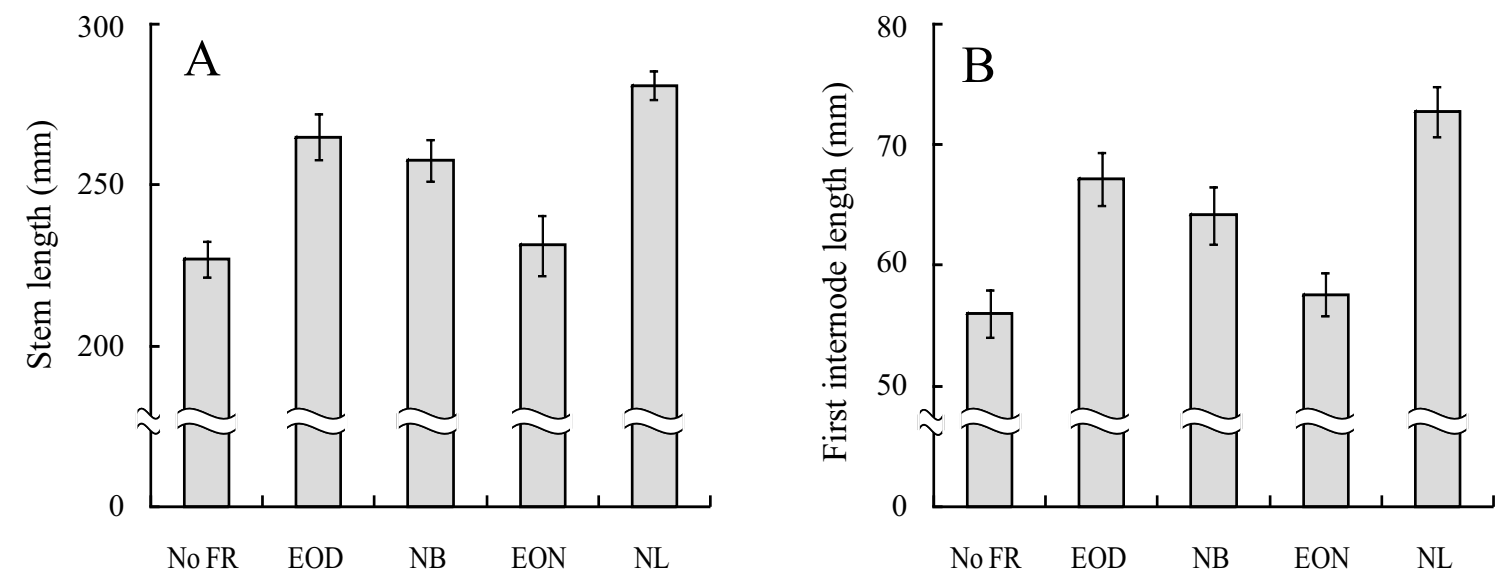

FR light treatment

Fig. 6. Effect of 4-h or continuous FR light treatments on the length of the stem (A) and the first internode (B) in the tulip cultivar "Leen van der mark"

The natural photoperiod was extended by exposure to light from FR fluorescent tubes applied throughout the night (night lighting, NL), a 4-h end-of-day period (EOD; from dusk), a night-break period (NB; from 2200 to 0200) or an end-ofnight period (EON; from $4 \mathrm{~h}$ before dawn). The PFD at the surface of the pot soil was $0.59 \mu \mathrm{mol} \mathrm{m}^{-2} \mathrm{~s}^{-1}$ All values are mean $\pm \operatorname{SE}(n=15)$.

urated at a relatively low PFD level. FR exposure throughout the entire night was found to produce maximal effect, but a brief 4-h exposure of FR at EOD and NB was also found to induce extension growth. It is expected that these data will be useful in developing FR lighting methods for the production of cut tulips.

Light is among the key environmental cues used by plants for making adjustments related to their growth and development. Plants have 3 major families of photoreceptors, including 2 types of near-ultraviolet/B-light receptors (cryptochrome and phototropin) and an R/FRlight receptor (phytochrome), which enable plants to gain information about their environments. When discussing light effects, it is important to consider which photoreceptor(s) are involved in light perception and which mechanism(s) are activated after perceiving light signals. Since UV-A, B, R, or FR light were found to affect extension growth (Fig. 3, 4), cryptochromes, phototropins and/or phytochromes are presumably involved in light perception by tulips. Conversely, these families of photoreceptors absorb little light in the $\mathrm{G}$ and $\mathrm{Y}$ regions, which may be relevant to the observation that these wavelengths have less pronounced effects on extension growth. Light signals through cryptochromes and phytochromes suppress extension growth in numerous darkgrown plants ${ }^{1,4,6,15,16,18,31}$. Our results, however, showed that night lighting with UV-A, B, R, and FR light promoted extension growth (Fig. 3, 4). This incompatibility is likely attributable to differences between light- and dark- grown plants as described in the introduction. Lightgrown plants under a natural sunshine photoperiod served as controls, and light treatments were conducted throughout the night in our experiments.

Extension growth is promoted in various plants when they grow under light with a low R:FR ratio (also known as the "FR-rich" condition) 9 . A period of FR night lighting and a brief 4-h exposure to EOD and NB FR light produced consistent effectiveness in promoting extension growth (Fig. 3, 4). Since phytochrome A and B (members of the phytochrome family) are considered to be mainly involved in the perception of FR light ${ }^{13,14,21}$, phytochrome A and/or phytochrome B likely mediated FR promotion in the extension growth of tulips. Phytochrome B shows R/FR photoreversibility and mediates the signal of the R:FR ratio. FR light promotes extension growth since a low R:FR ratio photoconverts a biologically active form of phytochrome $\mathrm{B}$ (which is responsible for inhibition of extension) to an inactive form. This effect of a low R:FR ratio can be reversed by subsequent exposure to light with a high R:FR ratio ${ }^{30}$. EON FR lighting had no effect on extension growth, although EOD and NB FR light were effective (Fig. 6). This indicates that the effect of EON FR lighting could be immediately reversed by subsequent exposure to R-rich sunlight. This evidence of $\mathrm{R} / \mathrm{FR}$ photoreversible control of extension growth provides strong evidence that phytochrome $\mathrm{B}$ is at least partly responsible for the response to FR exposures in the extension growth of tulips. 
GA, and auxin are important phytohormones involved in the regulation of extension growth in tulips ${ }^{20,28}$. Recent studies have indicated that light signals are involved in the regulation of biosynthesis and responses of phytohormones, especially GA (e.g. see Lau \& Deng ${ }^{17}$ ). Thus, the effects of light on extension growth are discussed with respect to phytohormones as follows. GA biosynthesis is up-regulated when FR-rich LD induce extension growth in many plants ${ }^{13,32,34}$. In light-grown Arabidopsis, phytochrome $\mathrm{B}$ induces petiole elongation through the up-regulation of a GA biosynthetic gene, AtGA20ox2, under FR-rich LD and EOD FR conditions ${ }^{13}$. Phytochrome B also regulates other components of GA signaling to alter the responsiveness to $\mathrm{GA}^{23}$. These mechanisms could be involved in FR-induced elongation in tulips.

The mechanisms of the night lighting of UV-A, B, and $\mathrm{R}$ in promoting extension growth are unknown, while the effectiveness of $\mathrm{R}$ night lighting in promoting extension growth appears inconsistent with the explanation involving the FR effect and R/FR photoreversibility of phytochrome B. However, there are probably different signal transduction pathways involved instead of a single pathway that is responsible for the effectiveness of FR. There are families of GA biosynthetic genes, including GA 3-oxidase and GA 20-oxidase genes, in Arabidopsis. These genes have different expression patterns and participate in distinct GA-regulated developmental processes throughout the life cycle of Arabidopsis. GA 3-oxidase genes are up-regulated in germinating seed by $\mathrm{R}$ light $^{33}$. In the case of GA 20-oxidase genes, AtGA20oxl mainly regulates internode and filament elongation, while AtGA20ox2 mainly regulates flowering time and silique length ${ }^{26}$ in addition to petiole length ${ }^{13}$. Transcript analysis indicates that regulation of the expression of these 2 genes by light differs. AtGA20ox1 expression increases during light periods with R-rich fluorescent tubes under SD conditions ${ }^{13}$. Conversely, AtGA20ox2 expression increases upon exposure to the FR-rich light condition $^{13}$ as cited above. $\mathrm{R}$ light possibly induces extension growth via the up-regulation of a member of the GA 3-oxidase family and/or GA 20-oxidase genes in tulips.

Light is a strong cue used in entrainment (synchronization) of the circadian clock. The circadian clock regulates GA biosynthesis ${ }^{2,13}$ and the expression of $A t G A$ 20ox1 is amplified with the circadian oscillation maintained under continuous R-rich fluorescent light ${ }^{13}$. Furthermore, the circadian clock regulates auxin signaling and responses ${ }^{5}$. Since the clock gene components of the circadian clock system are affected by light signaling through phytochromes and cryptochromes ${ }^{8,27}$, an explanation of increased extension growth under continuous
UV-A, B, and R light during the night could involve circadian clock-associated regulation of extension growth in tulips.

In conclusion, exposure of UV-A, B, R, and FR promotes extension growth in tulips. The most effective light was found to be FR. The quantitative effect and valid timing of FR exposure were successively demonstrated. These data are very useful for practical trials of FR lighting. Since the effect of the LD treatment was found to vary according to growing temperatures ${ }^{11}$, the FR effect presumably also varies in response to temperature conditions. Therefore, the FR lighting method must be optimized for use under commercial production conditions. Practical trials of FR treatments are now underway with the aim of developing a cultivation system under greenhouse conditions. Preliminary results indicate the benefit of FR treatments for producing long stems in several cultivars used for cut tulip production (T. Tsuji, data not shown).

\section{Acknowledgments}

We thank MOGI Hisakazu for excellent technical assistance with light treatments, Dr. ODA Atsushi for valuable comments on the manuscript, and KAMEI Setsuko and SUZUKI Tamaki for technical assistance with plant propagations.

\section{References}

1. Ahmad, M. \& Cashmore, A. R. (1993) HY4 gene of A. thaliana encodes a protein with characteristics of a blue-light photoreceptor. Nature, 366, 162-166.

2. Blázquez, M. A., Trénor, M. \& Weigel, D. (2002) Independent control of gibberellin biosynthesis and flowering time by the circadian clock in Arabidopsis. Plant Physiol., 130, 1770-1775.

3. Brøndum, J. J. \& Heins, R. D. (1993) Modeling temperature and photoperiod effects on growth and development of Dahlia. J. Amer. Soc. Hort. Sci., 118, 36-42.

4. Casal, J. J. \& Smith, H. (1989) Effects of blue light pretreatments on internode extension growth in mustard seedlings after the transition to darkness: Analysis of the interaction with phytochrome. J. Exp. Bot., 40, 893-899.

5. Covington, M. F. \& Harmer, S. L. (2007) The circadian clock regulates auxin signaling and responses in Arabidopsis. PLoS Biol., 5, 1773-1784.

6. Duke, S. O. \& Wickliff, J. L. (1969) Zea shoot development in response to red light interruption of dark-growth period. I. Inhibition of first internode elongation. Plant Physiol., 44, 1027-1030.

7. Erwin, J. E., Heins, R. D. \& Moe, R. (1991) Temperature and photoperiod effects on Fuchsia $\mathrm{x}$ hybrida morphology. J. Amer. Soc. Hort. Sci., 116, 955-960.

8. Fankhauser, C. \& Staiger, D. (2002) Photoreceptors in Arabidopsis thaliana: light perception, signal transduction and 
entrainment of the endogenous clock. Planta, 216, 1-16.

9. Franklin, K. A. \& Whitelam, G. C. (2005) Phytochromes and shade-avoidance responses in plants. Ann. Bot., 96, 169-175.

10. Garner, W. W. \& Allard, H. A. (1920) Effect of the relative length of day and night and other factors of the environment on growth and reproduction in plants. J. Agr. Res., 18, 553-606.

11. Hanks, G. R. \& Rees, A. R. (1979) Photoperiod and tulip growth. J. Hort. Sci., 54, 39-46.

12. Hanks, G. R. (1982) The response of tulips to gibberellins following different durations of cold storage. J. Hort. Sci., 57, 109-119.

13. Hisamatsu, T. et al. (2005) The involvement of gibberellin 20-oxidase genes in phytochrome-regulated petiole elongation of Arabidopsis. Plant Physiol., 138, 1106-1116.

14. Jackson, S. \& Thomas, B. (1997) Photoreceptors and signals in the photoperiodic control of development. Plant Cell Environ., 20, 790-795.

15. Kigel, J. \& Cosgrove, D. J. (1991) Photoinhibition of stem elongation by blue and red light: Effects on hydraulic and cell wall properties. Plant Physiol., 95, 1049-1056.

16. Laskowski, M. J. \& Briggs, W. R. (1989) Regulation of pea epicotyl elongation by blue light. Plant Physiol., 89, 293 298.

17. Lau, O. S. \& Deng, X. W. (2010) Plant hormone signaling lightens up: integrators of light and hormones. Curr. Opin. Plant Biol., 13, 571-577.

18. Liscum, E. et al. (1992) Genetic separation of phototropism and blue light inhibition of stem elongation. Plant Physiol., 100, 267-271.

19. Okubo, H. \& Uemoto, S. (1984) Effects of darkness on stem elongation in tulip. Sci. Hort., 23, 391-397.

20. Okubo, H. \& Uemoto, S. (1985) Changes in endogenous gibberellins and auxin activities during first internode elongation in tulip flower stalk. Plant Cell Physiol., 26, 709-719.

21. Quail, P. H. (2002) Phytochrome photosensory signalling networks. Nat. Rev. Mol. Cell Biol., 3, 85-93.

22. Rebers, M. et al. (1995) Gibberellin levels and cold-induced floral stalk elongation in tulip. Physiol. Plant., 94, 687-691.

23. Reed, J. W. et al. (1996) Phytochrome B affects responsiveness to gibberellins in Arabidopsis. Plant Physiol., 112, 337-342.

24. Rees, A. R. (1969) Effects of duration of cold treatment on the subsequent flowering of tulips. J. Hort. Sci., 44, 27-36.

25. Rietveld, P. L. et al. (2000) Low temperature sensing in tulip (Tulipa gesneriana L.) is mediated through an increased response to auxin. J. Exp. Bot., 51, 587-594.

26. Rieu, I. et al. (2008) The gibberellin biosynthetic genes $A t$ GA20ox1 and AtGA20ox2 act, partially redundantly, to promote growth and development throughout the Arabidopsis life cycle. Plant $J ., 53,488-504$.

27. Salomé, P. A. \& McClung, C. R. (2005) What makes the Arabidopsis clock tick on time? A review on entrainment. Plant Cell Environ., 28, 21-38.

28. Saniewski, M. \& De Munk, W. J. (1981) Hormonal control of shoot elongation in tulips. Sci. Hort., 15, 363-372.

29. Shima, K. et al. (2009) Effect of brief irradiation with farred light at end of day on stem elongation of spray type chrysanthemum in winter. Hort. Res. (Japan), 8, 335-340 [In Japanese with English summary].

30. Smith, H. (1995) Physiological and ecological function within the phytochrome family. Annu. Rev. Plant Physiol. Plant Mol. Biol., 46, 289-315.

31. Takano, M. et al. (2001) Isolation and characterization of rice phytochrome A mutants. Plant Cell, 13, 521-534.

32. Talon, M. \& Zeevaart, J. A. D. (1992) Stem elongation and changes in the levels of gibberellins in shoot tips induced by differential photoperiodic treatments in the long-day plant Silene armeria. Planta, 188, 457-461.

33. Yamaguchi, S. et al. (1998) Phytochrome regulation and differential expression of gibberellin $3 \beta$-hydroxylase genes in germinating Arabidopsis seeds. Plant Cell, 10, 2115 2126.

34. Zeevaart, J. A. D. \& Gage, D. A. (1993) ent-kaurene biosynthesis is enhanced by long photoperiods in the long-day plants Spinacia oleracea L. and Agrostemma githago L. Plant Physiol., 101, 25-29. 